\title{
CARACTERÍSTICAS FÍSICAS E NUTRICIONAIS DA MATRIZ DE ENCAPSULAMENTO NA PRODUÇÃO DE SEMENTES SINTÉTICAS DE PIMENTA-LONGA (Piper hispidinervum C. DC.) ${ }^{1}$
}

Rodrigo da Silva Guedes ${ }^{2}$, Frederico Henrique da Silva Costa ${ }^{3}$, Jonny Everson Scherwinski Pereira ${ }^{4}$

\begin{abstract}
RESUMO - A pimenta-longa (Piper hispidinervum C. DC.) é um arbusto da família Piperaceae, nativa da região amazônica, que vem despertando o interesse das indústrias de cosméticos e bioinseticidas pelo alto teor de safrol, óleo essencial extraído das folhas e talos. O objetivo do trabalho foi avaliar a influência de características físicas e nutricionais da matriz de encapsulamento durante a produção de sementes sintéticas de pimenta-longa. Sementes germinadas de pimenta-longa foram utilizadas como material de encapsulamento. Em ambos os experimentos, a influência da constituição (água ou meio Murashige e Skoog) e consistência da cápsula (alginato de sódio $1 \%$ ou $2 \%$ ) e do tempo de complexação (10, 20 e 30 min) em $\mathrm{CaCl}_{2}$, na abertura das cápsulas, foi avaliada. Depois de encapsulados, os materiais foram transferidos para frascos com meio de MS e mantidos em sala de crescimento, onde, quinzenalmente, foi avaliada a taxa de emergência e crescimento das plântulas encapsuladas. Verificou-se que o emprego de um endosperma artificial composto por $1 \%$ de alginato de sódio em meio de MS foi o tratamento que promoveu os melhores resultados para a emergência e posterior crescimento de plântulas oriundas de sementes sintéticas aos 30 dias da semeadura em meio MS sólido, independentemente do tempo de complexação utilizado.
\end{abstract}

Palavras-chave: Piper hispidinervum C. DC., sementes artificiais e unidades encapsuláveis.

\section{PHYSICAL AND NUTRITIONAL CHARACTERISTICS OF THE ENCAPSULATED MATRIX OF LONG PEPPER(Piper hispidinervum C. DC.) SYNTHETIC SEED PRODUCTION}

\begin{abstract}
Long pepper (Piper hispidinervum C. DC.) is a shrub of the Piperaceae family, native of the Amazonian region, with special interest of cosmetics and bio-insecticide industries due to its high concentration of safrol, an essential oil extracted from the leaves and stems. This work aimed to evaluate the physical and nutritional characteristics of the encapsulation matrix during the production of synthetic seeds of long pepper. Germinated long pepper seeds were used as vegetative material for encapsulation. For both experiments, the influence of capsule composition (water or MS) and consistency (sodium alginate at $1 \%$ or $2 \%$ ), complexation time in $\mathrm{CaCl}_{2}$ (10,20 and 30 minutes) and opening of the capsules were evaluated. After encapsulation, the materials were transferred to flasks with MS medium and maintained in a growth room, where the germination and growth rates of the encapsulated plantlets were evaluated every two weeks. We verified that the use of an artificial endosperm composed by $1 \%$ of sodium alginate in MS medium promoted the best results for the conversion and further growth of plants originated from synthetic seeds after 30 days of culture in solid MS medium, independently of the complexation time used.
\end{abstract}

Keywords: Piper hispidinervum C. DC., artificial seeds and encapsulated units.

\footnotetext{
${ }^{1}$ Recebido em 13.11.2006 e aceito para publicação em 24.05.2007.

${ }^{2}$ Programa de Pós-Graduação em Agronomia - Produção Vegetal da Universidade Federal do Acre (UFAC), Rio Branco-AC. E-mail: <rodrigo78br@yahoo.com.br>.

${ }^{3}$ Mestre em Fitotecnia pela Universidade Federal de Lavras (UFLA). Cx. Postal 3037 - 37200-000 Lavras-MG. E-mail: $<$ fredericohenrique@yahoo.com.br>.

${ }^{4}$ Embrapa Recursos Genéticos e Biotecnologia, Núcleo de Recursos genéticos, Laboratório de Cultura de Tecidos I. Bolsista de Produtividade em Pesquisa pelo CNPq. E-mail: <jonny@ cpafac.embrapa.br>.
} 


\section{INTRODUÇÃO}

A espécie Piper hispidinervum C. DC., popularmente conhecida como pimenta-longa, é uma planta arbustiva aromática que, nos últimos anos, tem despertado o interesse das indústrias de cosméticos e bioinseticidas. Isso porque o óleo essencial extraído de suas folhas e talos são ricos em safrol, importante metabólito secundário, cuja demanda tem sido crescente por parte da indústria química devido à obtenção de heliotropina e butóxido de piperonila (PBO), ingredientes essenciais à produção de fragrâncias e inseticidas biodegradáveis (WADT, 2001). Contudo, por se tratar de uma espécie ainda em processo de domesticação, é importante que pesquisas científicas envolvendo métodos mais eficientes de propagação e conservação, que possibilitem avanços ao melhoramento vegetal dessa espécie e ainda favoreçam a síntese de safrol, sejam realizadas.

Nesse contexto, pela sua importância, a aplicação de técnicas de cultura de tecidos vegetais é promissora à espécie, já que possui ampla utilização para a obtenção massal de propágulos com elevado padrão genético e fitossanitário e conservação in vitro de diversas espécies, incluindo as nativas (FORTES e PEREIRA, 2001; OLIVEIRA et al., 2003; COUTO et al., 2004). No entanto, os trabalhos in vitro já reportados com a espécie Piper hispidinervum C. DC. são poucos e se restringem a estudos sobre calogênese, cultivo de células em meio líquido e aspectos anatômicos (PESCADOR et al., 2000; SANTIAGO, 2003), havendo, portanto, a necessidade de mais pesquisas. Dentre as técnicas biotecnológicas, a tecnologia de sementes sintéticas representa importante ferramenta no estabelecimento de protocolos eficientes de micropropagação massal, tendo sido reportada com sucesso em várias espécies vegetais, entre as quais se destacam as dos gêneros Musa (GANAPATHI et al., 1992; HASSANEIM et al., 2005), Carica (CASTILLO et al., 1998), Ananas (SONEJI et al., 2002) e Feijoa (GUERRA et al., 2001), dentre outras. O uso e aprimoramento da técnica se justificam pelo baixo custo e rápida multiplicação dos propágulos, além de facilitar o transporte e troca de germoplasma entre instituições de pesquisa, podendo servir ainda como alternativa para a conservação de genótipos sob condições in vitro (SAIPRASAD, 2001), possibilitando a semeadura direta dos propágulos em campo, eliminando etapas de transplante e aclimatização (MARTIN, 2003). Adicionalmente, essa técnica pode ajudar no aumento do tempo entre subcultivos e reduzir a frequiência de riscos de variações genéticas (RANI et al., 1995).
Apesar de todo o potencial da técnica, são relativamente poucos os estudos acerca do tipo de explante, constituição e consistência da cápsula, condições de cultivo e armazenamento das unidades encapsuláveis. Em geral, as pesquisas sobre encapsulamento envolvem o emprego de embriões somáticos como fonte de explantes (CASTILLO et al., 1998; ARA et al., 1999), havendo, assim, poucos trabalhos utilizando outros tipos de explantes como unidades encapsuláveis (GANAPATHI et al., 1992; NASSAR, 2003; SONEJI et al., 2002). Como agente encapsulante, o alginato de sódio tem sido o mais empregado, fato atribuído à sua solubilidade à temperatura ambiente, habilidade de gel permeável com o cloreto de cálcio, boa propriedade geleificante, baixo custo, facilidade de uso e ausência de toxicidade (GUERRA et al., 1998). Outro fator a ser considerado é o tempo de complexação, ou seja, o tempo de exposição ao cloreto de cálcio, uma vez que exerce influência na taxa de emergência das unidades encapsuláveis (CASTILLO et al., 1998; PATEL et al., 2000).

Assim, este trabalho teve por objetivo avaliar o potencial de uso da tecnologia de sementes sintéticas como ferramenta alternativa a futuros trabalhos de produção de propágulos e conservação in vitro de pimenta-longa (Piper hispidinervum C. DC.). Para tanto, foi testada a influência de características físicas e nutricionais da matriz de encapsulamento na produção de sementes sintéticas de pimenta-longa a partir de sementes pré-germinadas.

\section{MATERIAL E MÉTODOS}

O experimento foi conduzido no Laboratório de Morfogênese e Biologia Molecular da Embrapa Acre, Rio Branco, AC. Como material vegetal para o encapsulamento, utilizaram-se sementes pré-germinadas de Piper hispidinervum com 21 dias de cultivo in vitro.

Sementes de Piper hispidinervum foram inicialmente desinfestadas por $1 \mathrm{~min}$ em álcool (70\%), $20 \mathrm{~min}$ em hipoclorito de sódio ( $50 \%$ da concentração comercial) e submetidas à tríplice lavagem em água destilada e autoclavada. Em seguida, foram colocadas para germinar em meio constituído pelos sais e vitaminas de MS (MURASHIGE e SKOOG, 1962), acrescido de 30 g.L L $^{-1}$ de sacarose e solidificado com 6 g. $\mathrm{L}^{-1}$ de ágar. $\mathrm{O}$ pH do meio foi ajustado para 5,8 $\pm 0,1$ antes da adição do agente geleificante, sendo posteriormente autoclavado a $121^{\circ} \mathrm{C}$ e $1,3 \mathrm{~atm}$ por $15 \mathrm{~min}$. 
Após três semanas de cultivo, sementes prégerminadas (Figura 1A) foram selecionadas visualmente com base no tamanho das plântulas (entre $0,5 \mathrm{~mm}$ ) para servirem como material vegetal no encapsulamento. Uma vez selecionadas, as plântulas foram misturadas à matriz de alginato de sódio e, com o auxílio de uma pipeta automática e ponteira autoclavada (ajustada para $350 \mu \mathrm{L}$ ), individualmente resgatadas e gotejadas em solução de $\mathrm{CaCl}_{2} \cdot 2 \mathrm{H}_{2} \mathrm{O}(50 \mathrm{mM})$, na qual permaneceram por um período determinado de acordo com os experimentos. Posteriormente à fase de complexação, as unidades encapsuláveis foram submetidas a três lavagens em água destilada e autoclavada para a retirada do excesso de $\mathrm{CaCl}_{2} \cdot 2 \mathrm{H}_{2} \mathrm{O}$. Uma vez obtidas as cápsulas (Figura 1C-D), procedeu-se à sua imersão em solução de $\mathrm{KNO}_{3}(100 \mathrm{mM})$ por $20 \mathrm{~min}$ para a descomplexação, sendo logo após submetidas à nova lavagem em água destilada e autoclavada e imediatamente transferidas para frascos de vidro de $250 \mathrm{~mL}$ de capacidade com $40 \mathrm{~mL}$ de meio de MS. Tanto a solução de alginato de sódio $\left(\right.$ Synth $\left.^{\circledR}\right)$ com os respectivos tratamentos quanto soluções de $\mathrm{CaCl}_{2} \cdot 2 \mathrm{H}_{2} \mathrm{O}$ e de $\mathrm{KNO}_{3}$ foram esterilizadas por autoclavagem a $121^{\circ} \mathrm{C}$ e $1,3 \mathrm{~atm}$, durante $15 \mathrm{~min}$.

No primeiro experimento, foi estudadas a influência da constituição (água ou meio MS), associado à consistência da cápsula (alginato de sódio Synth ${ }^{\circledR}$ a 1 ou $2 \%$ ). O tempo de complexação empregado foi de 15 min. Aos 15 e aos 30 dias da semeadura in vitro, as avaliações da emergência e altura das plântulas foram realizadas.

No segundo experimento, estudaram-se a constituição (água ou meio MS) e consistência da cápsula (alginato de sódio Synth ${ }^{\circledR}$ a 1 ou $2 \%$ ) (Figura 1B), associadas ao tempo de complexação (10, 20 e $30 \mathrm{~min}$ ). Após 30 dias da semeadura in vitro, procedeu-se à avaliação da porcentagem de emergência e altura das plântulas. Em ambos os experimentos, as culturas foram mantidas em sala de crescimento à temperatura de 25 $\pm 2{ }^{\circ} \mathrm{C}$, fotoperíodo de $16 \mathrm{~h}$ e intensidade luminosa de $30 \mathrm{mmol} \cdot \mathrm{m}^{-2} \cdot \mathrm{s}^{-1}$.

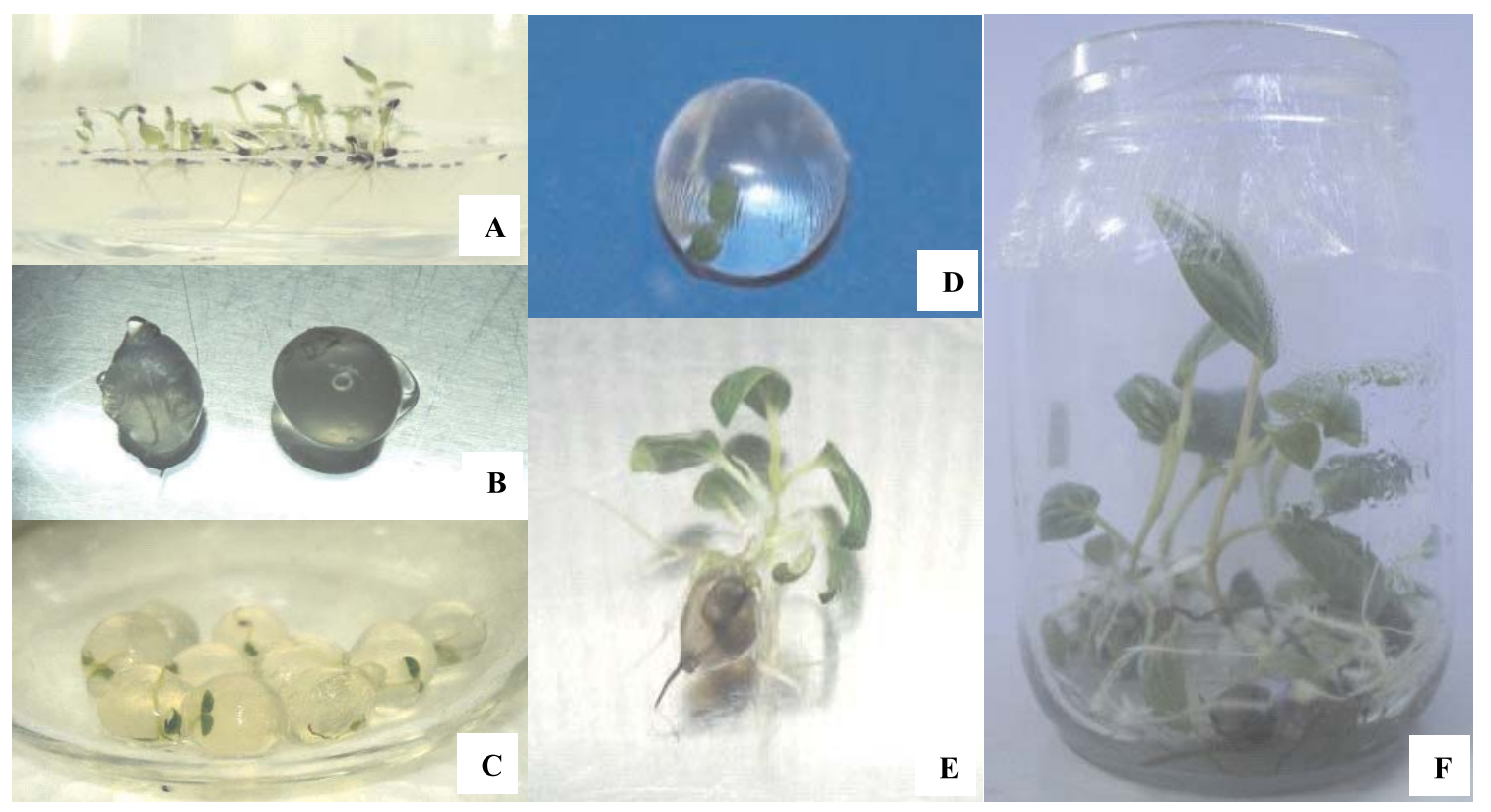

Figura 1 - Produção de sementes sintéticas de pimenta-longa: A) sementes pré-germinadas com 21 dias utilizadas como material para encapsulamento; B) aspecto de sementes pré-germinadas encapsuladas em diferentes concentrações de alginato de sódio ( $1 \%$ e 2\%); C-D) aspecto das plântula pré-germinadas encapsuladas; e E-F) plantas após 30 e 60 dias da emergência em meio de MS, prontas para a aclimatização.

Figure 1 -Production of synthetic long pepper seeds: A) 21-day pre-germinated seeds used as material for encapsulation; $B$ ) aspect of pre-germinated seeds encapsulated at different sodium alginate concentrations ( $1 \%$ and $2 \%$ ); $C$ $D)$ aspect of plantlets germinated after encapsulation; $E-F)$ plants after 30 and 60 days of culture in MS medium, ready for acclimatization. 
O delineamento experimental foi inteiramente casualizado, sendo cada tratamento representado por cinco repetições com 10 unidades encapsuladas por parcela. Os dados foram submetidos a uma análise de variância com o emprego do programa estatístico SANEST (ZONTA e MACHADO, 1984) e as médias, comparadas pelo teste de Tukey a $5 \%$ de probabilidade. Dados expressos em porcentagem (x) foram transformados em arco-seno $(\mathrm{x} / 100)^{0,5}$.

\section{RESULTADOS E DISCUSSÃO}

\section{Experimento 1}

Nenhuma interação significativa entre os fatores estudados (constituição x consistência x época) foi observada em relação ao porcentual de emergência das unidades encapsuláveis, diferentemente da altura de plântulas (Tabelas 1 e 2).

Quanto ao porcentual de emergência, efeito significativo da constituição da cápsula foi verificado apenas na concentração de $1 \%$ de alginato de sódio, na qual a introdução de meio MS à matriz de encapsulamento proporcionou resultado superior. Já quanto ao fator consistência, a matriz contendo $1 \%$ de alginato foi significativamente superior (Tabela 1). De acordo com Patel et al. (2000), a resistência e dureza da cápsula são um dos principais fatores a serem considerados durante o processo de encapsulamento, uma vez que exerceram influência decisiva na taxa de emergência e conversão das unidades encapsuláveis. Soneji et al. (2002), trabalhando com alginato de sódio $4 \%$ para o encapsulamento de microbrotos de abacaxi, verificaram cápsulas muito firmes, que mostraram baixa conversão em plântulas no momento da emergência.

Quanto à época de avaliação, aumento significativo no porcentual de emergência foi observado aos 30 dias da semeadura in vitro, com média de 79,1\% (Tabela 1). É provável que esse resultado tenha sido favorecido por um melhor crescimento dos explantes encapsulados e, dessa forma, aquisição da melhor capacidade para o rompimento das cápsulas.

Tabela 1 - Efeito da constituição da cápsula e concentração de alginato de sódio no percentual de germinação in vitro de sementes sintéticas de Piper hispidinervum após 15 e 30 dias em meio MS sólido

Table 1 - Effect of capsule constitution and sodium alginate concentration on in vitro germination percentage of Piper hispidinervum synthetic seeds after 15 and 30 days in solid MS medium

\begin{tabular}{|c|c|c|c|c|c|}
\hline \multirow[t]{3}{*}{ Época de avaliação (Dias) } & \multicolumn{2}{|c|}{ Alginato $1 \%$} & \multicolumn{2}{|c|}{ Alginato $2 \%$} & \multirow[t]{2}{*}{ Média (época) } \\
\hline & \multicolumn{4}{|c|}{ constituição } & \\
\hline & $\mathrm{H}_{2} \mathrm{O}$ & MS & $\mathrm{H}_{2} \mathrm{O}$ & MS & \\
\hline 15 & 67,9 & 94,7 & 57,9 & 57,6 & $69,5 b$ \\
\hline 30 & 88,4 & 100 & 67,9 & 60,1 & $79,1 \mathrm{a}$ \\
\hline Média (constituição) & $78,1 \mathrm{~B}$ & $97,3 \mathrm{~A}$ & $62,9 \mathrm{~A}$ & $58,8 \mathrm{~A}$ & \\
\hline Média (alginato) & & & & & \\
\hline
\end{tabular}

Médias seguidas por letras distintas minúsculas na vertical e maiúsculas na horizontal diferem estatisticamente entre si (P<0,05), pelo teste de Tukey.

Tabela 2 - Efeito da constituição da cápsula e concentração de alginato de sódio sobre a altura $(\mathrm{cm})$ de plântulas oriundas do encapsulamento de sementes pré-germinadas de Piper hispidinervum aos 15 e 30 dias em meio MS sólido

Table 2 - Effect of capsule constitution and sodium alginate concentration on height $(\mathrm{cm})$ of plantlets from pre-germinated seeds of Piper hispidinervum encapsulated after 15 and 30 days in solid MS medium

\begin{tabular}{|c|c|c|c|c|c|}
\hline \multirow{3}{*}{ Época de avaliação (Dias) } & \multicolumn{2}{|c|}{ Alginato $1 \%$} & \multicolumn{2}{|c|}{ Alginato $2 \%$} & \multirow{2}{*}{ Média (época) } \\
\hline & \multicolumn{4}{|c|}{ constituição } & \\
\hline & $\mathrm{H}_{2} \mathrm{O}$ & MS & $\mathrm{H}_{2} \mathrm{O}$ & MS & \\
\hline 15 & $0,4 \mathrm{bA}$ & $0,5 \mathrm{bA}$ & $0,4 \mathrm{bA}$ & $0,3 \mathrm{bA}$ & $0,4 b$ \\
\hline 30 & $1,1 \mathrm{aA}$ & $1,1 \mathrm{aA}$ & $0,7 \mathrm{aA}$ & $0,7 \mathrm{aA}$ & $0,9 \mathrm{a}$ \\
\hline Média (constituição) & $0,7 \mathrm{~A}$ & $0,8 \mathrm{~A}$ & $0,5 \mathrm{~A}$ & $0,5 \mathrm{~A}$ & \\
\hline Média (alginato) & \multicolumn{2}{|c|}{$0,8 \mathrm{~A}$} & \multicolumn{2}{|c|}{$0,5 \mathrm{~B}$} & \\
\hline
\end{tabular}

Médias seguidas por letras distintas minúsculas na vertical e maiúsculas na horizontal diferem estatisticamente entre si $(\mathrm{P}<0,05)$, pelo teste de Tukey.

R. Árvore, Viçosa-MG, v.31, n.6, p.1005-1011, 2007 
As taxas de emergência e crescimento dos explantes encapsulados têm sido variáveis entre os trabalhos já reportados. Fiegert (2000) obtiveram regeneração de $80 \%$ de sementes sintéticas de batata sobre meio MS sólido, enquanto Ganapathi et al. (1992) reportaram $60 \%$ de regeneração de brotos apicais de banana encapsulados. Já Soneji et al. (2002) observaram 100\% de regeneração de microbrotos encapsulados de abacaxi quando submetidos ao pré-tratamento em meio líquido constituído pelos sais e vitaminas de White, suplementado com 0,56 mM de inositol, 0,03 $\mathrm{M}$ de sacarose, 10,8 $\mu \mathrm{M}$ de ANAe 39,4 $\mu \mathrm{M}$ de AIB, sob agitação por $12 \mathrm{~h}$ e, em seguida, cultivados sobre meio basal de MS, adicionado de 0,56 mM de inositol, 0,06 $\mathrm{M}$ de sacarose, 9,67 $\mu \mathrm{M}$ de ANA e 9,84 $\mu \mathrm{M}$ de IBA e 9,29 $\mu \mathrm{M}$ de cinetina. Plantas produzidas por esse processo foram estabelecidas, com sucesso, em campo.

A baixa capacidade de emergência e regeneração observadas em alguns protocolos estabelecidos para a produção de sementes sintéticas é atribuída à ausência de um tecido nutritivo (endosperma sintético), tal como o endosperma da semente botânica (KUMAR ARUN et al., 2005), e ao obstáculo proporcionado pela cápsula à emergência de raízes e brotos. Portanto, o provimento de um endosperma sintético e a adoção de etapas que possibilitem o enfraquecimento ou ruptura da cápsula, como a descomplexação com $\mathrm{KNO}_{3}$, podem reverter essas limitações (ONISHI et al., 1994). De acordo com Adriani et al. (2000), a conversão em plântulas é o mais importante aspecto da tecnologia de sementes sintéticas e, apesar disso, um dos fatores limitantes do uso prático dessa ferramenta.

Em relação à altura de plântulas, nenhuma diferença significativa entre a constituição da cápsula foi verificada nas concentrações de alginato de sódio e épocas de avaliação (Tabela 2). Possivelmente esse resultado seja devido ao fato de que, após a protrusão radicular do interior das cápsulas e o conseqüente estabelecimento das raízes ao meio de germinação, todas as plântulas estiveram sob as mesmas condições de cultivo, absorvendo os mesmos nutrientes, independentemente da constituição interna das cápsulas. Já quanto à época de avaliação, diferença significativa foi observada, sendo as maiores alturas obtidas sempre aos 30 dias da semeadura (Tabela 2 e Figura 1E), o que ocorreu pelo maior tempo de permanência em meio de cultivo e, conseqüentemente, crescimento das plântulas.

\section{Experimento 2}

Neste ensaio, nenhuma interação significativa entre os fatores estudados (constituição x consistência $\mathrm{x}$ tempo de complexação) foi observada nas características avaliadas (Tabelas 3 e 4).

Tabela 3 - Efeito da constituição da cápsula, concentração de alginato e tempo de complexação na porcentagem de emergência in vitro de sementes sintéticas de Piper hispidinervum aos 30 dias em meio MS sólido

Table 3 - Effect of capsule constitution, alginate concentration and complexation time on the percentage of in vitro emergence of Piper hispidinervum synthetic seeds after 30 days in solid MS medium

\begin{tabular}{ccccc}
\hline \multirow{2}{*}{$\begin{array}{c}\text { Tempo de } \\
\text { complexação } \\
\text { (min) }\end{array}$} & \multicolumn{4}{c}{ Alginato 1\% } \\
\cline { 2 - 5 } & \multicolumn{5}{c}{ Alginato 2\% } \\
\hline & $\mathrm{H}_{2} \mathrm{O}$ & $\mathrm{MS}$ & $\mathrm{H}_{2} \mathrm{O}$ & $\mathrm{MS}$ \\
10 & 97,4 & 99,3 & 52,5 & 42,0 \\
20 & 88,3 & 100 & 67,9 & 60,1 \\
30 & 94,7 & 100 & 60,1 & 63,0 \\
\hline Média & $93,5 \mathrm{~B}$ & $99,8 \mathrm{~A}$ & $60,2 \mathrm{~A}$ & $55,0 \mathrm{~A}$ \\
(constituição) & \multicolumn{4}{c}{$57,6 \mathrm{~B}$} \\
\hline Média & \multicolumn{4}{c}{} \\
(alginato) & $96,6 \mathrm{~A}$ & & & \\
\hline
\end{tabular}

Médias seguidas por letras distintas dentro de cada fator diferem estatisticamente entre si $(\mathrm{P}<0,05)$, pelo teste de Tukey.

Tabela 4 - Efeito da constituição da cápsula, concentração de alginato e tempo de complexação sobre a altura (cm) de plântulas oriundas do encapsulamento de sementes pré-germinadas de Piper hispidinervum aos 30 dias em meio MS sólido

Table 4-Effect of capsule constitution, alginate concentration and complexation time on the height $(\mathrm{cm})$ of plantlets from pre-germinated seed encapsulation of Piper hispidinervum after 30 days using solid MS medium

\begin{tabular}{|c|c|c|c|c|}
\hline \multirow{2}{*}{$\begin{array}{c}\text { Tempo de } \\
\text { complexação } \\
(\min ) \\
\end{array}$} & \multicolumn{2}{|c|}{ Alginato $1 \%$} & \multicolumn{2}{|c|}{ Alginato $2 \%$} \\
\hline & \multicolumn{4}{|c|}{ constituição } \\
\hline & $\mathrm{H}_{2} \mathrm{O}$ & MS & $\mathrm{H}_{2} \mathrm{O}$ & MS \\
\hline 10 & 1,1 & 1,2 & 0,8 & 0,6 \\
\hline 20 & 1,1 & 1,1 & 0,7 & 0,7 \\
\hline 30 & 0,9 & 1,0 & 0,9 & 0,5 \\
\hline $\begin{array}{c}\text { Média } \\
\text { (constituiçãa) }\end{array}$ & $1,0 \mathrm{~A}$ & $1,1 \mathrm{~A}$ & $0,8 \mathrm{~A}$ & $0,6 \mathrm{~A}$ \\
\hline $\begin{array}{c}\text { Média } \\
\text { (alginato) }\end{array}$ & & & & \\
\hline
\end{tabular}

Médias seguidas por letras distintas dentro de cada fator diferem estatisticamente entre si $(\mathrm{P}<0,05)$, pelo teste de Tukey.

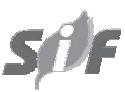

R. Árvore, Viçosa-MG, v.31, n.6, p.1005-1011, 2007 
Efeito significativo da constituição da matriz de encapsulamento sobre o porcentual de emergência foi observado apenas para a concentração de $1 \%$ de alginato, com 99,8\% de emergência. Quanto à consistência da cápsula, a concentração de $1 \%$ de alginato foi significativamente superior (Tabela 3). Já, em relação à altura das plântulas formadas, nenhuma diferença significativa foi verificada na constituição da cápsula, diferentemente do fator consistência, que promoveu altura significativamente superior com o acréscimo de $1 \%$ de alginato (Tabela 4). Provavelmente esse resultado seja devido ao maior porcentual de emergência das unidades encapsuláveis verificadas nessa condição, favorecendo, dessa maneira, o seu rápido crescimento.

Fatores como o tempo de exposição ao cloreto de cálcio (complexação), presença de sais nutritivos na matriz de encapsulamento e concentração de alginato de sódio, afetaram, de maneira significativa, a freqüência de regeneração de embriões de Carica papaya encapsulados (CASTILLO et al., 1998). Já embriões somáticos de Paulownia elongata encapsulados na matriz de encapsulamento contendo alginato de sódio (3\%) e sais de MS, complexados em $\mathrm{CaCl}_{2}(50 \mathrm{mM})$ por $30 \mathrm{~min}$, produziram cápsulas bastante firmes e também permitiram a conversão em plântulas. No entanto, o uso de baixas concentrações de alginato de sódio ( $1 \%$ a $2,5 \%$ ) não promoveu boa uniformidade e cápsulas suficientemente firmes, resultando em baixa freqüência de conversão dos embriões somáticos encapsulados (IPEKCI e GOZUKUMIZI, 2003). Esses autores verificaram ainda que a concentração do agente complexante $\left(\mathrm{CaCl}_{2}\right)$, assim como o tempo utilizado para a complexação, influencia a freqüência de conversão dos embriões somáticos, havendo a necessidade de redução no tempo de exposição ao cloreto de cálcio $\left(\mathrm{CaCl}_{2}\right)$ quando se usaram 60 ou $80 \mathrm{mM}$ de $\mathrm{CaCl}_{2} \mathrm{em}$ vez de $50 \mathrm{mM}$, pois a freqüência de conversão foi significativamente menor com as maiores concentrações. Além disso, também foi observado por esses autores que, embora tenha havido formação das cápsulas após 10 min de exposição ao $\mathrm{CaCl}_{2}$, estas não foram bastante firmes, enquanto após $1 \mathrm{~h}$ de exposição elas se apresentaram muito rígidas, conduzindo a uma baixa taxa de conversão.

\section{CONCLUSÃO}

O emprego de meio de cultura de MS na matriz de encapsulamento, com alginato de sódio $1 \%$, favorece a produção e regeneração de sementes sintéticas de
Piper hispidinervum C. DC., a partir de sementes prégerminadas, aos 30 dias da semeadura in vitro.

\section{AGRADECIMENTO}

Ao Conselho Nacional de Desenvolvimento Científico e Tecnológico (CNPq), pela concessão das bolsas de estudos.

\section{REFERÊNCIAS}

ADRIANI, M.; PICCIONI, E.; STANDARD, A. Effect of different treatments on the conversion of 'Hayward' kiwifruit synthetic seeds to whole plants following encapsulation of in vitro-derived buds. Journal of Crop and

Horticultural Science, v.28, p.59-67, 2000.

ARA, A.; JAISWAL, U.; JAISWAL, V. S. Germination and plantlet regeneration from encapsulated somatic embryos of mango (Mangifera indica L.). Plant Cell Reports, v.19, p.166-170, 1999.

CASTILLO, B.; SMITH, M. A. L.; YADAVA, U. L. Plant regeneration from encapsulated somatic embryos of Carica papaya L. Plant Cell Reports, v.17, p.172-176, 1998.

COUTO, J. M. F. et al. Desinfestação e germinação in vitro de sementes de mogno (Swietenia macrophylla King). Revista Árvore, v.28, n.5, p.633-642, 2004.

FIEGERT, A. K.; MIX-WAGNER, G.; VORLOP, K. D. Regeneration of Solanum tuberosum L. cv. Tomensa. Induction of somatic embryogenesis in liquid culture for the production of artificial seed. Landbauforsch, v.50, p.199-202, 2000.

FORTES, G. R. L.; PEREIRA, J. E. S. Preservação in vitro da batata com ácido acetilsalicílico e duas fontes de carboidrato. Pesquisa Agropecuária Brasileira, v.36, n. 10, p.1261-1264, 2001.

GANAPATHI, T. R. et al. Propagation of banana through encapsulated shoot tips. Plant Cell Reports, v.11, n.11, p.571-575, 1992.

GUERRA, M. P.; TORRES, A. C.; TEIXEIRA, J. B. Embriogênese somática e sementes sintéticas. In: TORRES, A. C.; CALDAS, L. S.; BUSO, J. A (Ed). Cultura de tecidos e transformação genética de plantas. Brasília: Embrapa, 1998. v.2. p.533-568. 
GUERRA, M. P. et al. Somatic embryogenesis in Feijoa sellowiana: Genotype response, Auxinic shock and synthetic seeds. Revista Brasileira de Fisiologia Vegetal, v.13, n.2, p.117-128, 2001.

HASSANEIN, A. M. et al. Micro-propagation factors essential for massal production of synthetic seeds in banana. Journal of Plant Biotechnology, v.7, n.3, p.1-7, 2005.

IPEKCI, Z.; GOZUKIRMIZI, N. Direct somatic embryogenesis and synthetic seed production from Paulownia elongata. Plant Cell

Reports, v.22, p.16-24, 2003.

KUMAR ARUN, M. B.; VAKESWARAN, V.; KRISHNASAMY, V. Enhancement of synthetic seed conversion to seedlings in hybrid rice. Plant Cell, Tissue and Organ Culture, v.81, n.1, p.97-100, 2005.

MARTIN, K. P. Clonal propagation, encapsulation and reintroduction of Ipsea malabarica (Reichb. F.) J. D. HOOK, an endangered orchid. In Vitro Cellular and Developmental Biology Plant, v.39, p.322-326, 2003.

MURASHIGE, T.; SKOOG, F. A revised medium for rapid growth and bioassays with tobacco tissue cultures. Physiologia Plantarum, v.15, p.473-97, 1962.

OLIVEIRA, A. J. B. et al. In vitro multiplication of Tabernaemontana fuchsiaefolia L. (Apocynaceae). Revista Árvore, v.27, n.4, p.421-425, 2003.

ONISHI, N.; SAKAMOTO, Y.; HIROSAWA, T. Synthetic seeds an application of mass production of somatic embryos. Plant Cell, Tissue and Organ Culture, v.39, n.2, p.137-145, 1994.

PATEL, A. V. et al. A novel encapsulation technique for the production of artificial seeds. Plant Cell Reports, v.19, n.9, p.868-874, 2000.
PESCADOR, R. et al. Biotecnologia da Piper hispidinervum - Pimenta longa.

Biotecnologia Ciência e

Desenvolvimento, v. 15, p.18-23, 2000.

RANI, V.; PARIDA, A.; RAINA, S. N. Random amplified polymorphic DNA (RAPD) markers for genetic analysis in micro-propagated plant of Populus deltoids March. Plant Cell Reports.v.14, p.459-462, 1995.

SAIPRASAD, G. V. S. Artificial seeds and their application. Resonance, p.39-47, 2001.

SANTiAgO, E. J. A. Caracterização morfológica e bioquímica de calos de pimenta longa (Piper hispidinervum Candolle, De Candolle). 2003. 162f. Tese (Doutorado em Fitotecnia) - Universidade Federal de Lavras, Lavras, 2003.

SONEJI, J. R.; RAO, P. S.; MHATRE, M. Germination of synthetic seeds of pineapple (Ananas comosus L. Merr.) Plant Cell Reports, v.20, n.10, p.891-894, 2002.

STANDARDI, A.; PICCIONI, E. Recent perspectives on synthetic seed technology using non embryogenic in vitro-derived explants. International Journal of Plant Science, v.159, n.6, p.968-978, 1998.

WADT, L. H. O. Estrutura genética de populações naturais de pimenta longa (Piper hispidinervum C. DC.), visando seu uso e conservação. 2001. 95f. Tese (Doutorado em Genética) - Escola Superior de Agricultura “Luiz de Queiroz”, Piracicaba, 2001.

ZONTA, E. P.; MACHADO, A. A. SANEST Sistema de Análise Estatística para Microcomputadores. Pelotas, Universidade Federal de Pelotas, 1984. 138p. 
